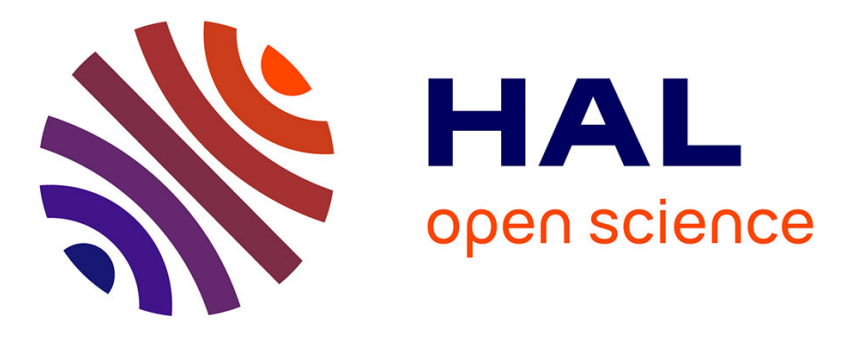

\title{
Design of stainless steel porous surfaces by oxide reduction with hydrogen
}

\author{
Valentin Badin, Entela Diamanti, Pierre Forêt, Matthieu Horgnies, Evelyne \\ Darque-Ceretti
}

\section{- To cite this version:}

Valentin Badin, Entela Diamanti, Pierre Forêt, Matthieu Horgnies, Evelyne Darque-Ceretti. Design of stainless steel porous surfaces by oxide reduction with hydrogen. Materials \& Design, 2015, 86, pp.765-770. 10.1016/j.matdes.2015.07.142 . hal-01183387

\section{HAL Id: hal-01183387 \\ https://hal-mines-paristech.archives-ouvertes.fr/hal-01183387}

Submitted on 11 Aug 2015

HAL is a multi-disciplinary open access archive for the deposit and dissemination of scientific research documents, whether they are published or not. The documents may come from teaching and research institutions in France or abroad, or from public or private research centers.
L'archive ouverte pluridisciplinaire HAL, est destinée au dépôt et à la diffusion de documents scientifiques de niveau recherche, publiés ou non, émanant des établissements d'enseignement et de recherche français ou étrangers, des laboratoires publics ou privés. 


\section{Design of stainless steel porous surfaces by oxide reduction with hydrogen}

Valentin Badin, Entela Diamanti, Pierre Forêt, Matthieu Horgnies, Evelyne Darque-Ceretti

$$
\text { Valentin Badin }
$$

MINES ParisTech, PSL - Research University, CEMEF - Centre for material forming, CNRS UMR 7635, CS10207 rue Claude Daunesse 06904 Sophia Antipolis Cedex, France valentin.badin@mines-paristech.fr

\section{Entela Diamanti}

Linde AG, Carl-von-Linde-Str. 25, 85716 Unterschleissheim, Germany entela.diamanti@linde.com

Pierre Forêt

Linde AG, Carl-von-Linde-Str. 25, 85716 Unterschleissheim, Germany pierre.foret@linde-gas.com

Matthieu Horgnies

Lafarge Centre de Recherche, 95 rue du Montmurier, 38291 Saint Quentin Fallavier, France matthieu.horgnies@lafarge.com

$$
\text { Evelyne Darque-Ceretti }
$$

MINES ParisTech, PSL - Research University, CEMEF - Centre for material forming, CNRS UMR 7635, CS10207 rue Claude Daunesse 06904 Sophia Antipolis Cedex, France Evelyne.darque-ceretti@mines-paristech.fr

Key Words: Stainless steel, surface, porosity, oxidation, reduction, hydrogen

\section{Highlights:}

- 1 A new method to create metal porous surfaces is investigated

- 2 It is achieved using high temperature hydrogen reduction on oxide scales formed on stainless steels

- 3 Pore characteristics and formation mechanism are discussed

- 4 This study intends to be a basis for potential applications 


\begin{abstract}
A new method to create porous surfaces on stainless steel by reducing oxide scales with hydrogen at $1100{ }^{\circ} \mathrm{C}$ has been investigated. Mercury Intrusion Porosimetry (MIP) along with Scanning Electron Microscopy (SEM) have been used to successfully study the porosity of the surfaces. Two different sets of parameters led to different morphologies. The first type of surface results from a 5 min reduction of a wüstite $\mathrm{FeO}$ surface oxide layer and provides smooth micrometer scale pores with a Gaussian distribution size. The second type of surface results from a $3 \mathrm{~h}$ reduction of a chromium rich oxide layer and provides three different micrometer scale pore size distributions with burst morphology. The volume of the porosity has been compared to its precedent oxide scale volume. The non-stoichiometry of wüstite is believed to be the main factor influencing the difference in the pore creation mechanism as compared to the mechanism of reduction from chromium-rich oxide.
\end{abstract}

\title{
1. Introduction
}

Producing porous surfaces on metals and alloys has a wide range of applications. Improved surface areas can enhance adhesion, heat exchange or catalytic performance among other useful properties. The methods to achieve this result are numerous [1] such as metal sintering and foaming. Exploring a new route using gaseous oxide reduction is proposed in this study. This paper aims to characterize the porous surfaces created, as a step toward understanding and controlling their formation.

Reducing certain oxides in an atmosphere such as $\mathrm{H}_{2}$ and $\mathrm{CO}$ at high temperature can generate porous material. This phenomenon has been studied in the past especially because of iron ore reduction [2-5]. Investigation on pure iron oxides has been carried further [6-9], focusing on the origin of the different pore morphologies. The same phenomenon has inspired the design of porous surfaces on stainless steels in order to increase the specific surface area of the samples.

The process involves two steps. In the first step an oxide scale is built using specific steel grade and oxidation conditions. This step has been studied in previous investigations [10, 11]. In the second step, after obtaining the oxide scale on a significant thickness, samples have been reduced using an adapted reduction time to obtain satisfactory morphologies. These morphologies have been evaluated first with the FEG-SEM (Field Emission Gun - Scanning Electron Microscopy) and optical observations of the cross-sections prior to further characterization.

In order to evaluate the pore dimension, the surface area measurement using the Brunauer-Emmett-Teller $\left(\mathrm{N}_{2}\right.$-BET) adsorption method had to be excluded due to the total surface area of the samples being too small to achieve the required level of accuracy. Indeed, that particular technique is better suited to powders or entirely porous materials. Mercury Intrusion Porosimetry (MIP) has therefore been employed to characterize the size of the pores, their distribution and the amount of porosity formed in the porous layer. While MIP is often used to characterize porous materials such as plaster mortars or concrete $[12,13]$, it has also been used to characterize porous iron successfully $[4,14]$.

EDS (Energy Dispersive Spectroscopy) mapping of a cross-section and X-Ray Diffraction (XRD) with grazing incidence angle have been undertaken to help establish the 
nature of the proposed mechanisms. The two mechanisms of pore formation observed in this study are discussed in order to support further work to improve or modify the properties of these surfaces.

\section{Experimental procedures}

\subsection{Surface treatment parameters}

Two sets of parameters have been established to obtain satisfactory porous morphologies. Both oxidation and reduction have been operated in a belt furnace, in two separate steps. The treatment characteristics given hereafter are summarized in Table 1.

\subsubsection{Type 1 performed on a breakaway type oxide scale}

An AISI 316L austenitic stainless steel has been used. A first treatment of $5 \mathrm{~min}$ oxidized the surface. The oxidizing atmosphere used was a flow of argon plus $5 \%$ of water vapor at $1100{ }^{\circ} \mathrm{C}$. The oxide scale results from a breakaway type oxidation, in which the top layer is only composed of wüstite $\mathrm{FeO}$, an iron oxide. The inner oxide layer is mainly composed of $(\mathrm{Fe}, \mathrm{Cr})_{3} \mathrm{O}_{4}$ spinels. The oxide scale is presented in Fig. 1.a. Further information on this type of oxide scale can be found in a previous publication [10] focused on their characterization.

After cooling, a subsequent reduction of $5 \mathrm{~min}$ was used. The reducing atmosphere applied was a flow of $3 \mathrm{~m}^{3} / \mathrm{h}$ of pure $\mathrm{H}_{2}$ at $1100{ }^{\circ} \mathrm{C}$. The dew point was set at $-30^{\circ} \mathrm{C}$.

\subsubsection{Type 2 performed on a Cr-rich oxide scale}

An AISI 441 ferritic stainless steel has been used for its different behavior towards oxidation. A first treatment of 30 min oxidized the surface. The oxidizing atmosphere was similar to the one used in Type 1. The oxide scale resulting is presented Fig. 1.b and is mainly composed of chromium and manganese oxides. That type of oxide scale has been investigated in depth and previously published [11].

After cooling, a subsequent reduction of $3 \mathrm{~h}$ was applied. The reducing atmosphere was similar to the one used for the austenitic steel.

\subsection{Test methods}

\subsubsection{Scanning Electron Microscopy (SEM) and Energy Dispersive Spectroscopy (EDS)}

The surfaces of the samples were characterized using a high-resolution field effect gun scanning electron microscope (FEG-SEM Zeiss SUPRA 40) with an accelerating voltage of 3 $\mathrm{keV}$. Images were recorded in Secondary Electron mode (SE). The EDS analysis of the crosssection was performed using a Philips XL 30 SEM. The related image was recorded in Back Scattering Electron mode (BSE). 


\subsubsection{Optical microscopy}

A Leica inverse optical microscope was used to characterize the cross-sections. Magnification of $1000 \times$ was employed, with the help of the function "Multifocus" from the Leica LAS image analyzing program. The cross-sections of the samples were produced using a tilt of 60 degrees to double the apparent observed oxide thickness. The scale presented in the optical micrography pictures is halved, to correspond to the actual oxide thickness.

\subsubsection{Mercury Intrusion Porosimetry (MIP)}

The porous surfaces were investigated using the MIP technique (Autopore IV from Micromeritics, USA). The pressure range of the porosimeter was from sub ambient up to 400 $\mathrm{MPa}$, covering the pore diameter range from about $0.3 \mu \mathrm{m}$ to $3 \mu \mathrm{m}$. Tests were carried out on multiple processed plates of $20 \times 9 \times 1 \mathrm{~mm}$ and $10 \times 9 \times 1 \mathrm{~mm}$. All the samples were dried overnight in an oven at $45{ }^{\circ} \mathrm{C}$ before being introduced into the MIP cell. In order to characterize a significant surface area of each sample (and then obtain a more reliable result about the surface porosity), more than twenty plates were used to fill the MIP cell. The advancing/receding contact angle selected was 154 degrees as recommended by D.J. Wright for stainless steel [15] which is similar to the material forming the pores. Tests were undertaken on reference samples to identify and subsequently discount the effects caused by the use of a large group of small plates.

\subsubsection{X-Ray Diffraction}

XRD experiments were realized on a Philips X'Pert Pro MPD. X-Ray radiation was $\mathrm{Cu}-\mathrm{K}_{\alpha}$. A grazing incidence angle of 0.2 degrees has been used to consider external oxide only. Most of the signal should result from the analysis of the first few hundreds nanometers. However, the roughness of the analyzed surface prevents one from assessing an accurate analysis depth. This roughness is evaluated to be between 1 and $2 \mu \mathrm{m}$ by optical microscopy.

\section{Results and discussion}

\subsection{Influences of the treatments on the morphology}

In order to differentiate the two porous surfaces, SEM-FEG pictures are presented in Fig. 2 in order to provide an initial observation of both morphologies. Fig. 2.a and Fig. 2.b present the Type 1 surface after treatment, at different scales. The porosity on this surface appears to consist of micrometer scale pores. Irregularity on the amount of visible pore distribution can be seen on a local point of view but the distribution remains homogeneous through the entire sample, as seen in Fig. 2.a. At high magnification (Fig. 2.b), iron grain boundaries are visible. The grains of wüstite existing before the reduction are not observed.

Optical microscopy observation of a cross-section of Type 1 is also presented in Fig. 3.a. Pores can be observed down to $5 \mu \mathrm{m}$ across two parts of the oxide scale, the entire top 
layer of former wüstite crystals and partially across the inner layer of $\mathrm{Fe}-\mathrm{Cr}$ spinels. The porosity growing through this second layer is particularly interesting because the presence of chromium does not completely prevent the mechanism from occurring, even for short durations like $5 \mathrm{~min}$.

The Type 2 surface is presented at the same magnification in Fig. 2.c and Fig. 2.d. The morphology is very different compared to Type 1. Instead of smooth and curvy pores, the pores observed in this case appear more like burst pores. This morphology is homogenous through the entire sample (Fig. 2.c). No grain boundary can be observed.

Cross-sections of Type 2 are presented in Fig. 3.b. The former oxide boundaries are not visible. Previously, the oxide was $5 \mu \mathrm{m}$ thick (Fig. 1.b) but the new layer formed is no thicker than $2 \mu \mathrm{m}$.

\subsection{Characterization of the surface porosity by MIP}

The MIP results are presented in Fig. 4 and Table 2 in order to evaluate the pore distribution and characteristics induced by the treatment conditions. First, no specific porosity has been highlighted on the reference samples (before any treatment) made of austenitic or ferritic steel.

For Type 1, a single pore size distribution is highlighted by MIP. The distribution curve (Fig. 4) showed a critical pore radius of about $1.05 \mu \mathrm{m}$. The distribution of the pore size follows a Gaussian-like curve with a minimal pore size of $0.35 \mu \mathrm{m}$ and a maximum of 1.85 $\mu \mathrm{m}$. That pore size distribution can be compared directly with the observation done by FEGSEM. The shape of the pores is homogeneous in the porous layer despite the throats of the pores (Fig. 2.b) being sometimes wider than the highest values from the MIP - over $2 \mu \mathrm{m}$. One can therefore conclude that the throats are not representative.

For Type 2, three critical pore diameters, of respectively $0.55,1$ and $3.85 \mu \mathrm{m}$, seem to be observed on the distribution curve in Fig. 4. The pore size distribution, in particular the one centered to $1 \mu \mathrm{m}$, does not follow a Gaussian shape. From small to large critical pore size, the gap between the minimal and maximal value increases. For instance, the critical pore distribution center on a diameter of $0.55 \mu \mathrm{m}$ has a gap of $0.35 \mu \mathrm{m}$ whereas the critical pore diameter of $3.85 \mu \mathrm{m}$ has a gap of $2.4 \mu \mathrm{m}$. The largest pores are thus more dispersed in terms of size.

The total porosity volumes, measured by MIP located at the surface of each type of treated samples, are compared in Table 2. The total porosity volumes are then $0.1 \%$ and $0.04 \%$ for Type 1 and Type 2 samples, respectively. These values take into account that almost all the volume of material introduced into the MIP cell is not porous. Therefore, the volume of the porosity has to be compared with the volume of the former oxide.

\subsection{Estimation of the porosity volume relative to oxide scales}

For Type 1, the samples are $1 \mathrm{~mm}$ thick with two times $10 \mu \mathrm{m}$ of former oxides (on average), which correspond to $2 \%$ of the total sample volume. For Type 2 , it is two times 5 $\mu \mathrm{m}$ of former oxides, which correspond to $1 \%$ of the total sample volume. We do not consider 
the small sides of the samples and the difference in density between oxides and bulk; the ratio is therefore an approximation to get an idea of the missing matter compared to what would be a full surface.

Relative to their respective former oxide volume, one obtains $5 \%$ porosity volume for Type 1 and 4\% for Type 2. However, if we look at the reduced cross-section (Fig. 3.a) for Type 1, the pores are not deeper than $5 \mu \mathrm{m}$ into the former oxide because the former $\mathrm{Fe}-\mathrm{Cr}$ spinel layer is not entirely reduced. In the porous part; this increases the relative porosity volume to $10 \%$. Applying the same reasoning for Type 2 (Fig. 3.b), pores are observable down to $2 \mu \mathrm{m}$. The boundary between the former oxide and the bulk is not observable anymore as it has been destroyed by the mechanism of pore formation. This also corresponds to a relative porosity volume of $10 \%$ in the relevant area. The porosity volume relative to their immediate surroundings is therefore similar but the Type 1 absolute value is greater.

The level of connectivity between the pores cannot be established precisely, whatever the type studied. This prevents one from presenting accurate 'specific surface area' results.

\subsection{Mechanisms of pores creation}

\subsubsection{Type 1 pore formation}

A similar type of porosity as the one observed on Type 1 has been studied decades ago in order to understand the reduction of iron ore [2-5]. The main focus of these studies was the final step in the reduction of iron ore, the transition from wüstite to iron. As in our Type 1 samples the external oxide layer is pure wüstite, most of the literature on the phenomenon can be applied here in spite of the different substrate. Indeed, the external layer after treatment has been proven to be pure iron using XRD, as can be seen in Fig. 5. The generally accepted theory is that this results from the reduction of non-stoichiometric oxide [16]. It has been observed on Mo and Ni oxides for instance [17, 18]. Wüstite is a strongly non-stoichiometric oxide where iron ions can be either divalent or trivalent. It requires vacancies to equilibrate the charge in the $\mathrm{FeO}$ lattice when an $\mathrm{Fe}$ ion is trivalent. When oxygen is removed by hydrogen to form $\mathrm{H}_{2} \mathrm{O}$, it creates a gradient of divalent $\mathrm{Fe}$ ions concentration and their diffusion. This step is correlated with vacancies diffusing in the opposite direction. The presence of instabilities, such as cavities, spreads the iron ions laterally. They then germinate into new grains of iron that constitute the walls of the pores. This smooth scenario is in agreement with a Gaussian distribution of the pores. More details on the theory can be found in the literature where different morphologies can occur depending on the parameters $[6-9,19$, 20]. It does mean the size and the shape of the pores can be controlled further to obtain a behavior adjusted to the needs. For instance, lowering slightly the temperature and/or the reduction time could increase the specific surface area by diminishing the size of the pores. The volume of porosity can also be increased by providing a thicker oxide.

\subsubsection{Type 2 pore formation}

As seen in a previous work [11], the former oxide of Type 2 was a mix of mainly $\mathrm{Cr}_{2} \mathrm{O}_{3}$ and some $\mathrm{Mn}-\mathrm{Cr}$ spinel oxides. These oxides are thermodynamically very stable and 
are thus difficult to reduce. They require a prolonged exposure to $\mathrm{H}_{2}$ above $1000{ }^{\circ} \mathrm{C}$ [21] in the case of $\mathrm{Cr}_{2} \mathrm{O}_{3}$. However, the difference in the morphologies should not be caused by the kinetic difference. As seen above, the previous mechanism of pore creation on the Type 1 sample rely on the diffusion of vacancies in a non-stoichiometric oxide. The main compounds of the Type 2 oxide layer are stoichiometric. There are therefore almost no vacancies enabling the same type of porosity. The burst structure observed with the SEM is an indication that allows one to understand the mechanism. In addition, this is supported by the findings depicted in Fig. 6. In this figure, a cross-section of a sample reduced for only $1 \mathrm{~h}$ is shown, with the EDS elemental mapping of $\mathrm{O}$ and Fe. When the oxygen image is bright, the former oxide layer is not yet reduced for this duration. The iron is always present on the external part of the scale, no matter if the underlying layer is reduced or not. Therefore, the suggested scenario is the formation of a dense layer of metallic iron from Fe ions diffusing through the $\mathrm{Cr}-\mathrm{Mn}$ oxide scale before the reduction of the scale occurs. Consequently hydrogen diffuses through this newly formed layer to reach the non-reduced $\mathrm{Cr}-\mathrm{Mn}$ oxides, forming $\mathrm{H}_{2} \mathrm{O}$ vapor bubbles. Finally, successive bursting occurs, explaining the burst morphology in Fig. 2.d. While the bulk and the scale are very different, the scenario would be similar to the breakdown process presented by St John et al. [7]. In order to help establish the credibility of this mechanism, the three differing values of pore size distribution, as well as the nonGaussian distribution were examined. They reveal a reaction that does not follow a smooth transformation resulting from a diffusion process as seen on Type 1. The successive bursting steps scenario mentioned above is in agreement with this observation as is the appearance of the burst morphology. Such a morphology should be more difficult to control as it is not possible to adjust the parameters drawing on the existing literature, as for Type 1. Thickening the former oxide is also difficult [11] as it reaches a steady state. Using that method to improve the amount of porosity is not as relevant. However, the benefit is a different composition of the walls of the pores. The $3 \mathrm{~h}$ reduction at high temperature is likely to induce a strong diffusion of the main elements. The walls are therefore likely to be constituted of a mix of $\mathrm{Fe}$ and $\mathrm{Cr}$. The presence of $\mathrm{Cr}$ may influence the applications chosen for the treated surfaces, particularly in the presence of water.

\section{Conclusions}

Reducing stainless steel oxides with hydrogen at $1100{ }^{\circ} \mathrm{C}$ can be used as a new way to form porous surfaces on stainless steels. Two very different morphologies have been obtained by reducing different oxides. The porous surfaces obtained have been characterized using combined methods. The two types obtained can be described as given below:

-Type 1 samples, performed on austenitic steel, are obtained essentially from the reduction of wüstite $\mathrm{FeO}$. The pores are micrometer scale and smoothly shaped. The mechanisms for the formation of these kinds of pores centers on the non-stoichiometry of the former oxide. The inner layer of spinels oxide also forms pores during the treatment.

-Type 2 samples, performed on ferritic steel, are obtained from the reduction of a chromium rich oxide. The pores are also micrometer scale, but three different distribution sizes are 
observed. The mechanism for the formation of these pores is thought to be the successive bursting of a dense reduced layer, thus explaining the difference of morphology with Type 1 .

The total porosity volume obtained depends on the thickness of the former oxide and the mechanisms of pore formation involved. With the parameters employed, Type 1 has presented a larger volume of porosity. The size of the pores and the thickness of the former oxide should be controllable. Type 2 may be less porous and more difficult to control but its surface is different and may lead to different uses. The successful use of MIP to characterize the porous surfaces is therefore now seen as a key method for the comparison of samples.

\section{Acknowledgments}

Authors wish to thank Linde AG for financing this research and the kind help of Sylvette Chiale and Michel Ney (Lafarge Research Center) for the MIP experiments.

\section{References}

[1] L. F. Dumée, L. He, B. Lin, F.-M. Allioux, J.-B. Lemoine, L. Velleman, F. She, M. C. Duke, J. D. Orbell, G. Erskine, P. Hodgson, S. Gray, L. Kong, The fabrication and surface functionalization of porous metal frameworks - a review, Journal of Materials Chemistry A 48 (2013) 15185-15206

[2] L. Von Bogdandy, H.-J. Engell, The reduction of iron ores, Springer-Verlag (1971)

[3] E. T. Turkdogan, J. V. Vinters, Gaseous reduction of iron oxides: 1. reduction of hematite in hydrogen, Metallurgical Transactions 2 (1971) 3175-3188

[4] E. T. Turkdogan, R. G. Olsson and J. V. Vinters, Gaseous reduction of iron oxides.2: pore characteristics of iron reduced from hematite in hydrogen, Metallurgical Transactions 2 (1971) 3189-3196

[5] E. T. Turkdogan, J. V. Vinters, Gaseous reduction of iron oxides.3: reduction-oxidation of porous and dense iron oxides and iron, Metallurgical Transactions 3 (1972) 1561-1574

[6] D. H. St John, P. C. Hayes, Microstructural features produced by the reduction of wüstite in hydrogen/water gas mixtures, Metallurgical Transactions B 13 (1982) 117-124

[7] D. H. St John, S. P. Matthew and P. C. Hayes, The breakdown of dense iron layers on wüstite in $\mathrm{CO} / \mathrm{CO}_{2}$ and $\mathrm{H}_{2} / \mathrm{H}_{2} \mathrm{O}$ systems, Metallurgical Transactions B 15 (1984) 701-708

[8] D.H. St. John, S. R Matthew, and P. C. Hayes, Establishment of product morphology during the initial stages of wüstite reduction, Metallurgical Transactions B 15 (1984) 709-717

[9] S. P. Matthew, T. R. Cho, P. C. Hayes, Mechanisms of porous iron growth on wüstite and magnetite during gaseous reduction, Metallurgical Transactions B 21 (1990) 733-741

[10] V. Badin, E. Diamanti, P. Forêt, E. Darque-Ceretti, Water vapor oxidation of ferritic 441 and austenitic $316 \mathrm{~L}$ stainless steels at $1100{ }^{\circ} \mathrm{C}$ for short duration, Procedia Materials Science (2015) to be published DOI: 10.1016/j.mspro.2015.04.006

[11] V. Badin, E. Diamanti, P. Forêt, E. Darque-Ceretti, Characterization of oxide scales formed on ferritic stainless steel 441 at $1,100{ }^{\circ} \mathrm{C}$ under water vapor, Oxidation of Metals 82 (2014) 347-357

[12] M. Horgnies, S. Gutiérrez-González, A. Rodríguez b, V. Calderón, Effects of the use of polyamide powder wastes on the microstructure and macroscopic properties of masonry mortars, Cement \& Concrete Composites 52 (2014) 64-72 
[13] A. Rodríguez, S. Gutiérrez-González, M. Horgnies, V. Calderón, Design and properties of plaster mortars manufactured with ladle furnace slag, Materials and Design 52 (2013) 987994

[14] I.-J. Moon, C.-H. Rhee, D.-J. Min, Reduction of hematite compacts by $\mathrm{H}_{2}$-CO gas mixtures, Steel research 69 (1998) 302-306

[15] D. J. Wright, Hysteresis of the angle of contact of mercury against steel, Proceedings of the Physical Society B 68 (1955) 297-303

[16] C. Wagner, Mechanism of the reduction of oxides and sulfides to metals, Journal of Metals (1952) 214-216

[17] T. Matsuda, Y. Hirata, H. Itoh, H. Sakagami, N. Takahashi, Effect of reduction temperature on the transformation of $\mathrm{MoO}_{3}$ to $\mathrm{MoO}_{x}$ with a large surface area, Microporous and Mesoporous Materials 42 (2001) 337-344

[18] T. Hidayat, M. A. Rhamdhani, E. Jak, P. C. Hayes, Investigation of nickel product structures developed during the gaseous reduction of solid nickel oxide, Metallurgical and Materials Transactions B 40 (2009) 462-473

[19] P. C. Hayes, Stability criteria for product microstructures formed on gaseous reduction of solid metal oxides, Metallurgical and Materials Transactions B 41 (2010) 19-34

[20] P. C. Hayes, Analysis of product morphologies and reaction mechanisms on gaseous reduction of iron oxides, Steel Research International 82 (2011) 480-493

[21] W. F. Chu, A. Rahmel, The kinetics of the reduction of chromium oxide by hydrogen, Metallurgical Transactions B 10 (1979) 401-407 

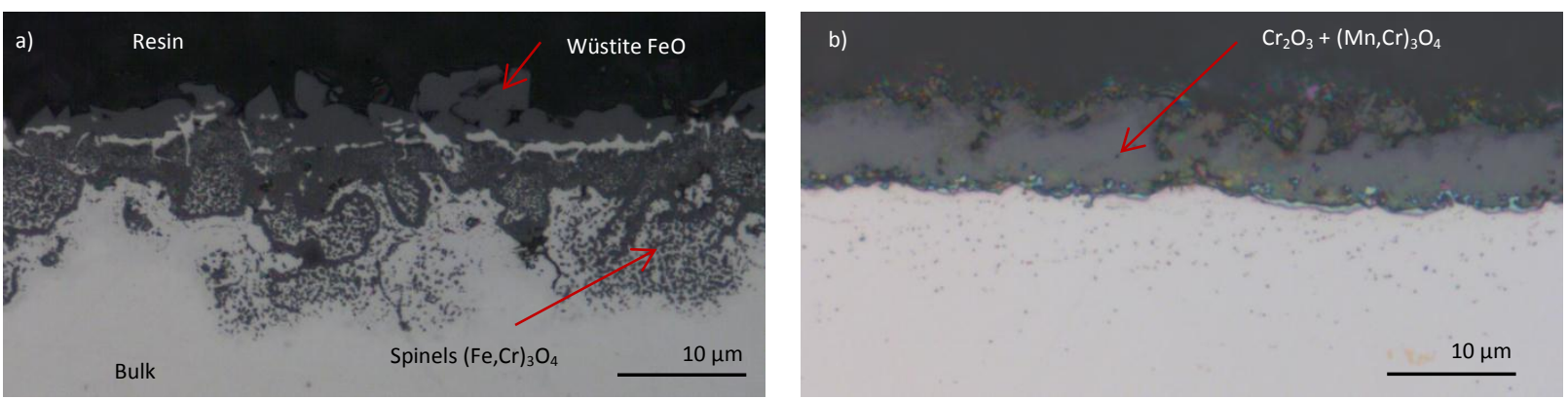

Fig. 1: Optical microscopy observations of cross-sections of the samples before reduction: (a) Oxide scale of Type 1 (before reduction): austenitic steel after 5 min of oxidation at $1100{ }^{\circ} \mathrm{C}$ with $\mathrm{Ar}+5 \%$ $\mathrm{H}_{2} \mathrm{O}$; (b) Oxide scale of Type 2 (before reduction): ferritic steel after $30 \mathrm{~min}$ of oxidation at $1100{ }^{\circ} \mathrm{C}$ with $\mathrm{Ar}+5 \% \mathrm{H}_{2} \mathrm{O}$
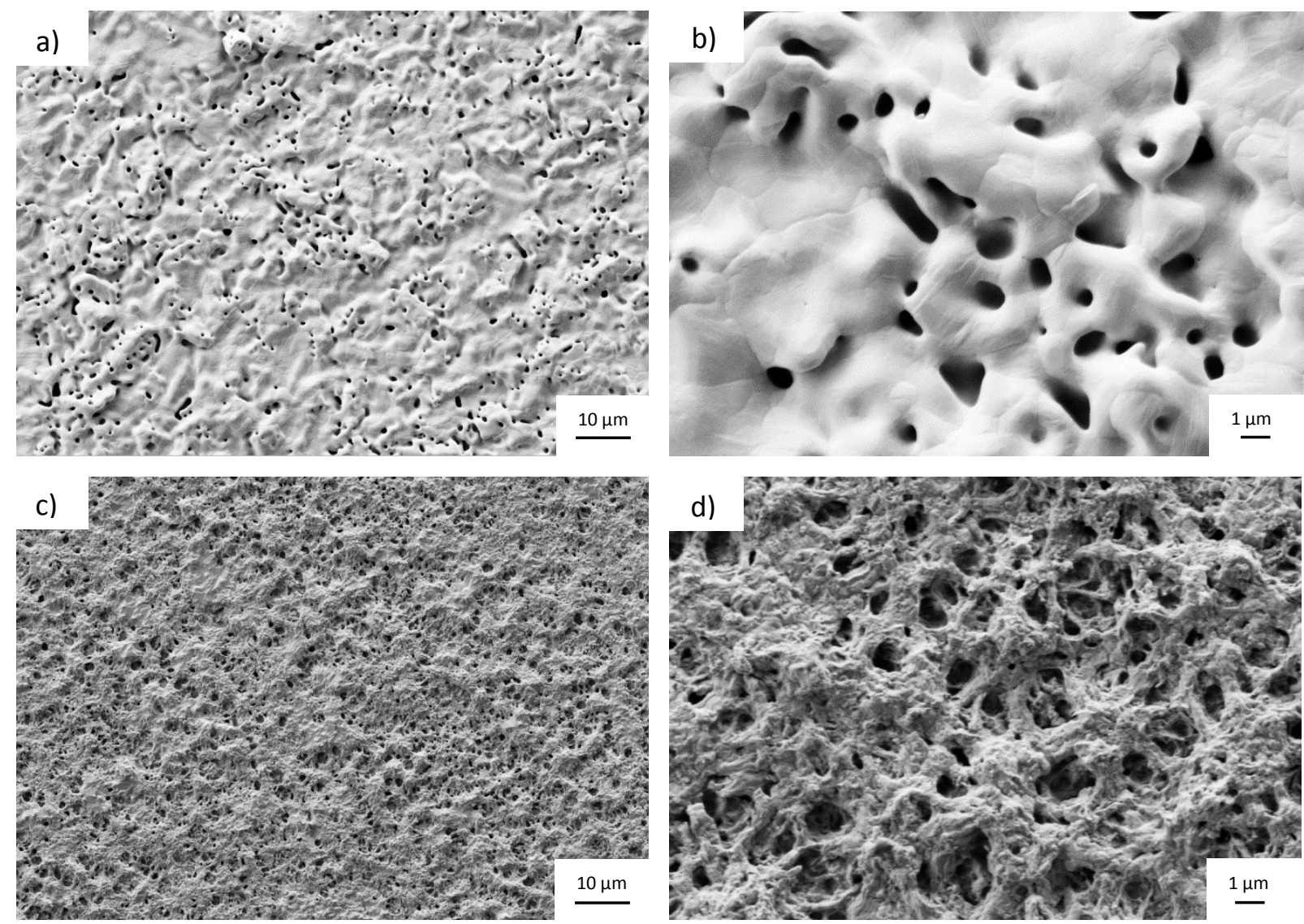

Fig. 2: Secondary electron mode SEM-FEG observations of: (a) and (b) Type 1 surface; (c) and (d) Type 2 surface. 

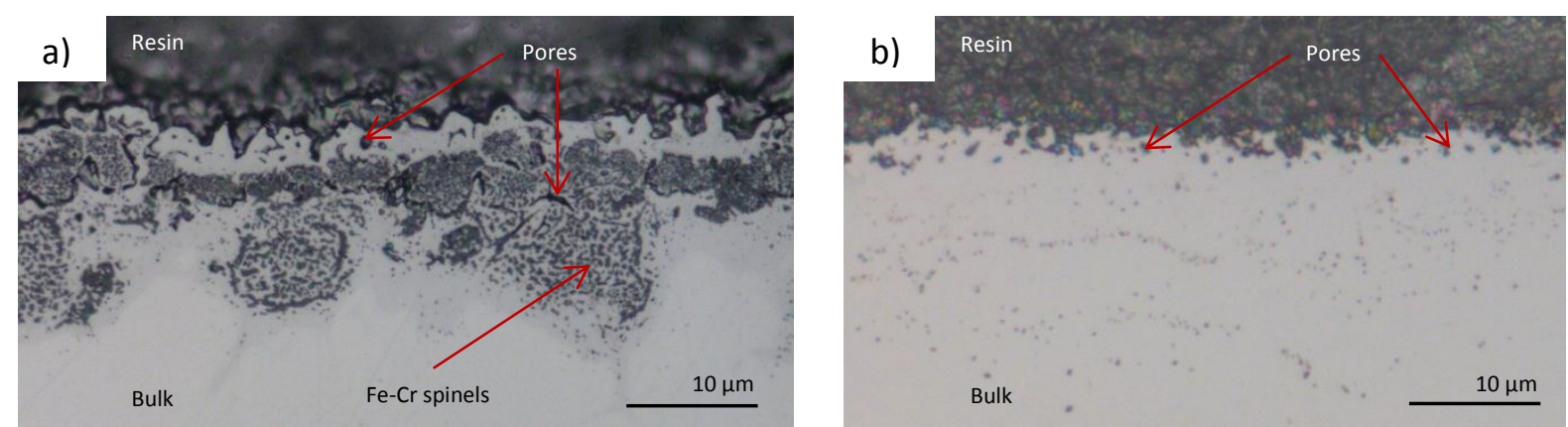

Fig. 3: Optical microscope observations of: (a) Cross-section of Type 1 surface; (b) Cross-section of Type 2 surface.

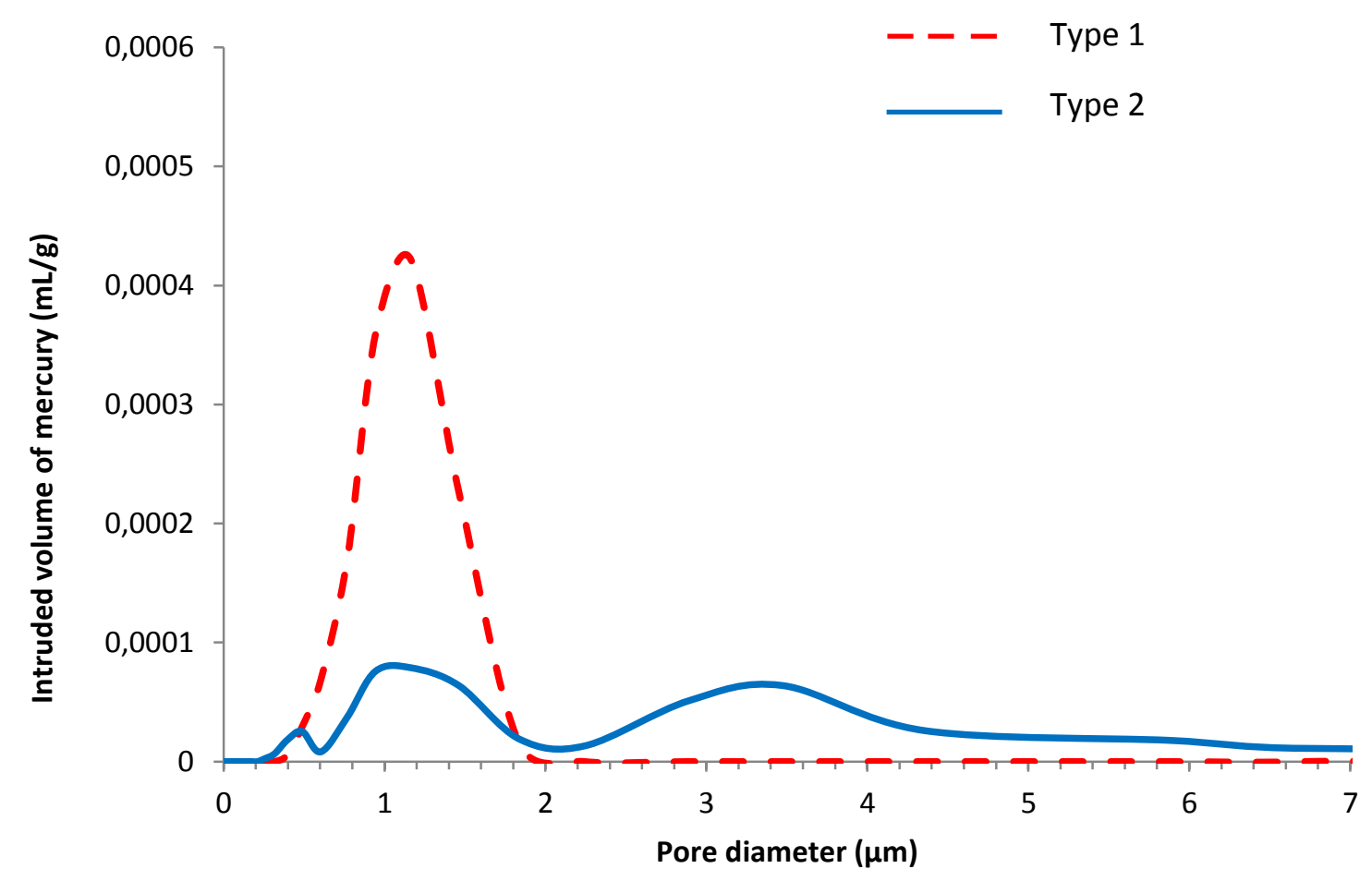

Fig. 4: Differential distribution curves measured by MIP for both type of treated samples: (in red) Type 1; (in blue) Type 2 


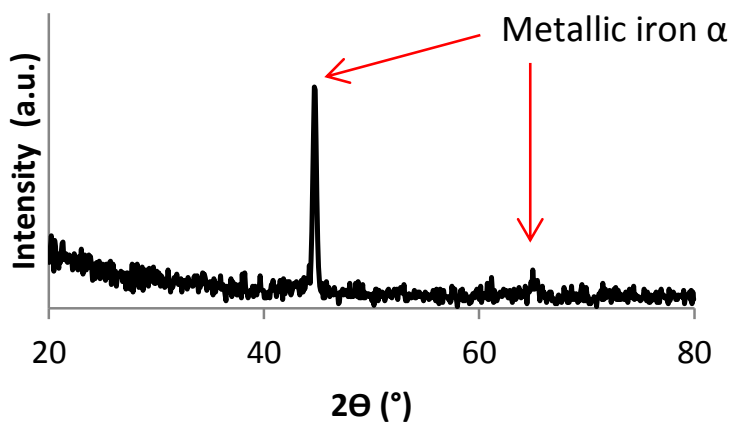

Fig. 5: XRD spectrum of Type 1 surface using a grazing incidence angle of 0.2 degrees.
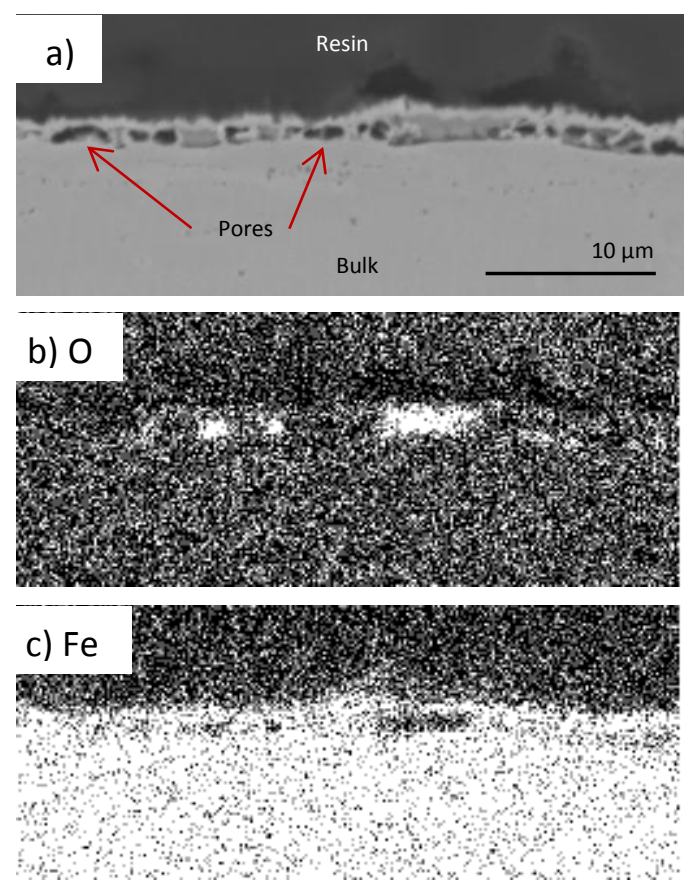

Fig. 6: Cross-section observed by SEM and analysed by EDS of the Type 2 surface after $1 \mathrm{~h}$ of reduction: (a) backscattering electron mode image; (b) EDS mapping of oxygen; (c) EDS mapping of iron. 
Table 1: Samples and parameters

\begin{tabular}{cccccc}
\hline Samples & Stainless steel & Main elements & Oxidation parameters & Oxides main characteristics & Reduction Parameters \\
\hline \multirow{2}{*}{ Type 1} & AISI 316L & Fe & $1100^{\circ} \mathrm{C}$ & Breakaway type & $1100^{\circ} \mathrm{C}$ \\
& Austenitic & $18 \% \mathrm{Cr}$ & $\mathrm{Ar}+5 \% \mathrm{H}_{2} \mathrm{O}$ & External layer FeO & $\mathrm{Pure} \mathrm{H}_{2}$ \\
& & $8 \% \mathrm{Ni}$ & $5 \mathrm{~min}$ & Inner layer $(\mathrm{Fe}, \mathrm{Cr})_{3} \mathrm{O}_{4}$ & $5 \mathrm{~min}$ \\
\hline \multirow{2}{*}{ Type 2 } & AISI 441 & $\mathrm{Fe}$ & $1100^{\circ} \mathrm{C}$ & & $1100^{\circ} \mathrm{C}$ \\
& Ferritic & $18 \% \mathrm{Cr}$ & $\mathrm{Ar}+5 \% \mathrm{H}_{2} \mathrm{O}$ & $\mathrm{Cr}_{2} \mathrm{O}_{3}+(\mathrm{Mn}, \mathrm{Cr})_{3} \mathrm{O}_{4}$ & $\mathrm{Pure}_{2}$ \\
& & & $30 \mathrm{~min}$ & & $3 \mathrm{~h}$ \\
\hline
\end{tabular}

Table 2: Pore characteristics of the treated samples from MIP results

\begin{tabular}{ccccccc}
\hline Samples & $\begin{array}{c}\text { Critical pore } \\
\text { diameter }(\mu \mathrm{m})\end{array}$ & $\begin{array}{c}\text { Minimal pore } \\
\text { diameter }(\mu \mathrm{m})\end{array}$ & $\begin{array}{c}\text { Gap between min } \\
\text { and } \max (\mu \mathrm{m})\end{array}$ & $\begin{array}{c}\text { Total porosity } \\
\text { volume }(\%)\end{array}$ & $\begin{array}{c}\text { Former oxide } \\
\text { thickness }(\mu \mathrm{m})\end{array}$ & $\begin{array}{c}\text { Porosity volume } \\
\text { relative to oxide } \\
\text { scale }(\%)\end{array}$ \\
\hline Type 1 & 1.05 & 0.35 & 1.5 & 0.1 & 10 & 5 \\
Type 2 & $0.55 / 1 / 3.85$ & $0.25 / 0.6 / 2.1$ & $0.35 / 1.5 / 2.4$ & 0.04 & 5 & 4 \\
\hline
\end{tabular}

